\title{
Aragonitic dendritic prismatic shell microstructure in Thracia (Bivalvia, Anomalodesmata)
}

\author{
A. Checa ${ }^{1, *}$, E. M. Harper ${ }^{2}$, M. Willinger ${ }^{3,4}$ \\ ${ }^{1}$ Department of Stratigraphy and Paleontology, Universidad de Granada, Granada, Spain \\ ${ }^{2}$ Department of Earth Sciences, Cambridge University, Cambridge, UK \\ ${ }^{3}$ Centre for Research in Ceramics and Composite Materials, Universidade de Aveiro, Aveiro, Portugal \\ ${ }^{4}$ Department of Inorganic Chemistry, Fritz Haber Institute of the Max Planck Society, Berlin, Germany \\ ${ }^{*}$ Corresponding author: e-mail acheca@ugr.es,
}

Accepted 1 November 2011; Article first published online: 9 January 2012; Published March 2012

\begin{abstract}
The shells of most anomalodesmatan bivalves are composed of an outer aragonitic layer of either granular or columnar prismatic microstructure, and an inner layer of nacre. The Thraciidae is one of the few anomalodesmatan families whose members lack nacreous layers. In particular, shells of members of the genus Thracia are exceptional in their possession of a very distinctive but previously unreported microstructure, which we term herein "dendritic prisms." Dendritic prisms consist of slender fibers of aragonite which radiate perpendicular to, and which stack along, the axis of the prism. Here we used scanning and transmission electron microscopical investigation of the periostracum, mantle, and shells of three species of Thracia to reconstruct the mode of shell calcification and to unravel the crystallography of the dendritic units. The periostracum is composed of an outer dark layer and an inner translucent layer. During the free periostracum phase the dark layer grows at the expense of the translucent layer, but at the position of the shell edge, the translucent layer mineralizes with the units typical of the dendritic prismatic layer. Within each unit, the $c$-axis is oriented along the prismatic axis, whereas the $a$-axis of aragonite runs parallel to the long axis of the fibers. The six-rayed alignment of the latter implies that prisms are formed by $\{110\}$ polycyclically twinned crystals. We conclude that, despite its distinctive appearance, the dendritic prismatic layer of the shell of Thracia spp. is homologous to the outer granular prismatic or prismatic layer of other anomalodesmatans, while the nacreous layer present in most anomalodesmatans has been suppressed.
\end{abstract}

Keywords: biomineralization;bivalves;aragonite;crystallography

Bivalve shell microstructures have been widely investigated ever since Bøggild's seminal work of 1930 (e.g. Taylor et al., 1969, 1973; Carter, 1980, 1990). These investigations have recognised a wide range of different microstructural types (both aragonitic and calcitic) and, generally, bivalves comprise of at least two different microstructural types, arranged in separate layers within the shell. It is clear that the precise combination of these have both adaptive and phylogenetic significance (Taylor et al. 1969, 1973; Taylor \& Layman 1972; Carter et al. 2000; Schneider \& Carter 2001; Waller 2006)

It has been widely suggested that the primitive arrangement in molluscs was a prismato-nacreous shell, where both the outer prismatic and inner nacreous layers were aragonitic (e.g. Taylor 1973; Wingstrand 1985; Salvini-Plawen \& Steiner 1996; Geiger et al. 2008). However, recent genetic (Jackson et al. 2010), immunohistochemical (Marie et al. 2009) and paleontological evidence (Vendrasco et al. 2011) suggests nacre evolved independently in the different groups.
The anomalodesmatan bivalves comprise a rather heterogeneous group of what are today often rather specialised taxa (including deep-sea carnivores and the bizarre tube-dwelling 'watering-pot' shells), which nonetheless form a monophyletic grouping of 15 families within the basal part of the Heterodont clade (see Harper et al. 2006 for a review). All anomalodesmatans have wholly aragonitic shells and for most taxa, for example Lyonsia, Myadora, Thraciopsis and Pandora, the microstructure of the external shell layer appears to be composed of columnar aragonitic prisms (although it has not been described formally), with nacre layers internally (Taylor et al. 1973; Prezant 1981). Evidence from fossil material suggests that this arrangement was present in early Palaeozoic anomalodesmatans (Morris et al. 1991). However, some taxa (e.g. Entodesma, Thracia, Poromya and Cuspidaria) are described as having an "homogeneous" microstructure (Taylor et al. 1973, Prezant 1981), in particular in the outer shell layer. Detailed investigation of the homogeneous layer in the outer layer of Entodesma has revealed that in fact this 
material is composed of short prismatic units immersed in an organic matrix (granular prismatic; Harper et al. 2009). Subsequently, Checa \& Harper (2010) identified a similar microstructure in the external shell layer of Laternula.

In member of other anomalodesmatan families, such as the Thraciidae and Cuspidariidae, "homogeneous" microstructure occurs occurs widely throughout the shell, and for many of these taxa there is no nacre present (Harper et al. 2006). Here we concentrate on the "homogeneous" microstructure of thraciids, which is of particular interest because there is evidence that early Mesozoic thraciids had prismatonacreous shells (Taylor 1973; Runnegar 1974), and a suggestion that members of a few species retain some nacre (Marshall 2002; J.G. Carter, pers. comm.). We selected the Thraciidae, therefore, for further detailed investigation of "homogeneous" shell microstructure in order to understand its relationships (and possible homologies) to more "primitive" microstructures.

The Thraciidae comprises $\sim 17$ extant genera of moderately deeply burrowing bivalves. Despite their cosmopolitan distribution, largely in shallow subtidal soft-bottom communities, the family remains poorly known with relationships between taxa being uncertain. Indeed molecular analyses have failed to recover even the limited number of 'thraciid' taxa incorporated as monophyletic (Harper et al. 2006) and anatomical studies even within the genus Thracia have revealed significantly variable anatomical characters (Morton 1995; Sartori \& Domaneschi 2005).

The only detailed previous account on the microstructure of Thracia is that of Taylor et al. (1973) for $T$. convexa, T. phaseolina and T. villosiuscula, which were described as "homogeneous", composed of spherulites, which are in turn made up of smaller crystallites (their plate 13, figs. 1-4). Our initial investigations of thraciids revealed that they are composed of a single layer of units, each consisting of horizontal fibres which radiate from a central axis and are stacked up vertically, so that the units resemble 'christmas trees'. These units tend to be oriented with their long vertical axis more or less perpendicular to the shell surface, although there are a number of units obliquely to this or even parallel to the shell surface. Since these microstructures are totally unknown in both biogenic and abiogenic aragonite, the intention of this study is to describe them in detail and to determine both their relation to the periostracum, their crystallographic structure and their use as shell characters in phylogenetic analysis.

\section{Methods}

\section{Materials}

Microstructural details were assessed from different portions of fractured shells of three different species: Thracia similis COUTHOUY 1839 (collected from Río Negro province, Argentina), T. phaseolina (E1 Rompido, Huelva, Spain), and T. convexa (Belgium). Specimens were exam- ined using light microscopy, scanning electron microscopy (SEM), andtransmission electron microscopy (TEM). In addition, the mantle and periostracum were studied in a specimen of T. phaseolina collected alive (from Mill Bay, Salcombe, Devon, United Kingdom) and preserved in ethanol. We excised part of the ventral mantle, taking care to include the free periostracum as well as the shell margin. The sample was then prepared for TEM observation, as described below.

\section{Microscopy}

Specimens observed by SEM were coated with carbon with a Hitachi UHS evaporator. We used a field emission scanning electron microscope (Zeiss LEO Gemini 1530) to examine specimens.

For light microscopy and TEM, specimens were completely decalcified in EDTA, then postfixed in $2 \%$ osmium tetroxide for $2 \mathrm{~h}$ at $4^{\circ} \mathrm{C}$. Immediately after postfixation, the samples were washed three times (each wash of $15 \mathrm{~min}$ ) in distilled water at ambient temperature, and then dehydrated through immersion in a series of solutions of increasing ethanol concentrations $(70 \%, 90 \%$, and twice in $100 \%$ ), for $15 \mathrm{~min}$ in each. Samples were then infiltrated with a 1:1 mixture of $100 \%$ ethanol and Epon 812 resin prior to being embedded in $100 \%$ resin, which was then polymerized at $60^{\circ} \mathrm{C}$ for $48 \mathrm{hr}$. Sections were made using a diamond knife (DIATOME) in an ultramicrotome (LEICA Ultracut R). Semi-thin sections $(1 \mathrm{~lm})$ were stained with $1 \%$ toluidine blue and observed with an Olympus BX51 microscope. Ultrathin sections $(50 \mathrm{~nm})$ were stained with uranyl acetate $(1 \%)$, then lead citrate. They were later carbon- coated and observed with Zeiss EM 10C or Zeiss LEO $906 \mathrm{E}$ transmission electron microscopes at an accelerating voltage of $80 \mathrm{kV}$.

For high-resolution (HRTEM) and scanning TEM (STEM), shell samples were mechanically polished and then thinned down to electron transparency with a GATAN precision ion polishing system (PIPS) at the Fritz Haber Institute of the Max Planck Society in Berlin. STEM analysis was carried out using the Jeol 2200FS microscope at the Universidade de Aveiro, Portugal. Fast Fourier Transform (FFT) lattice spacings were obtained using DigitalMicrograph software (GATAN)

\section{Thermogravimetry}

The organic content of selected shell fragments was investigated by thermogravimetry. Two samples (25-45 $\mathrm{mg}$ ) of shell were taken from each of two shells of Thracia similis and powdered before analysis using a thermogravimetric analyser (Shimadzu TGA-50H, Univ. Granada) over a temperature range from $25^{\circ} \mathrm{C}$ to $950^{\circ} \mathrm{C}$. Significant weight losses at temperatures between $150^{\circ} \mathrm{C}$ (above water loss) and $500^{\circ} \mathrm{C}$ (when $\mathrm{CaCO}_{3}$ decomposition begins) were used to calculate the percent organic matter (Table 1). 

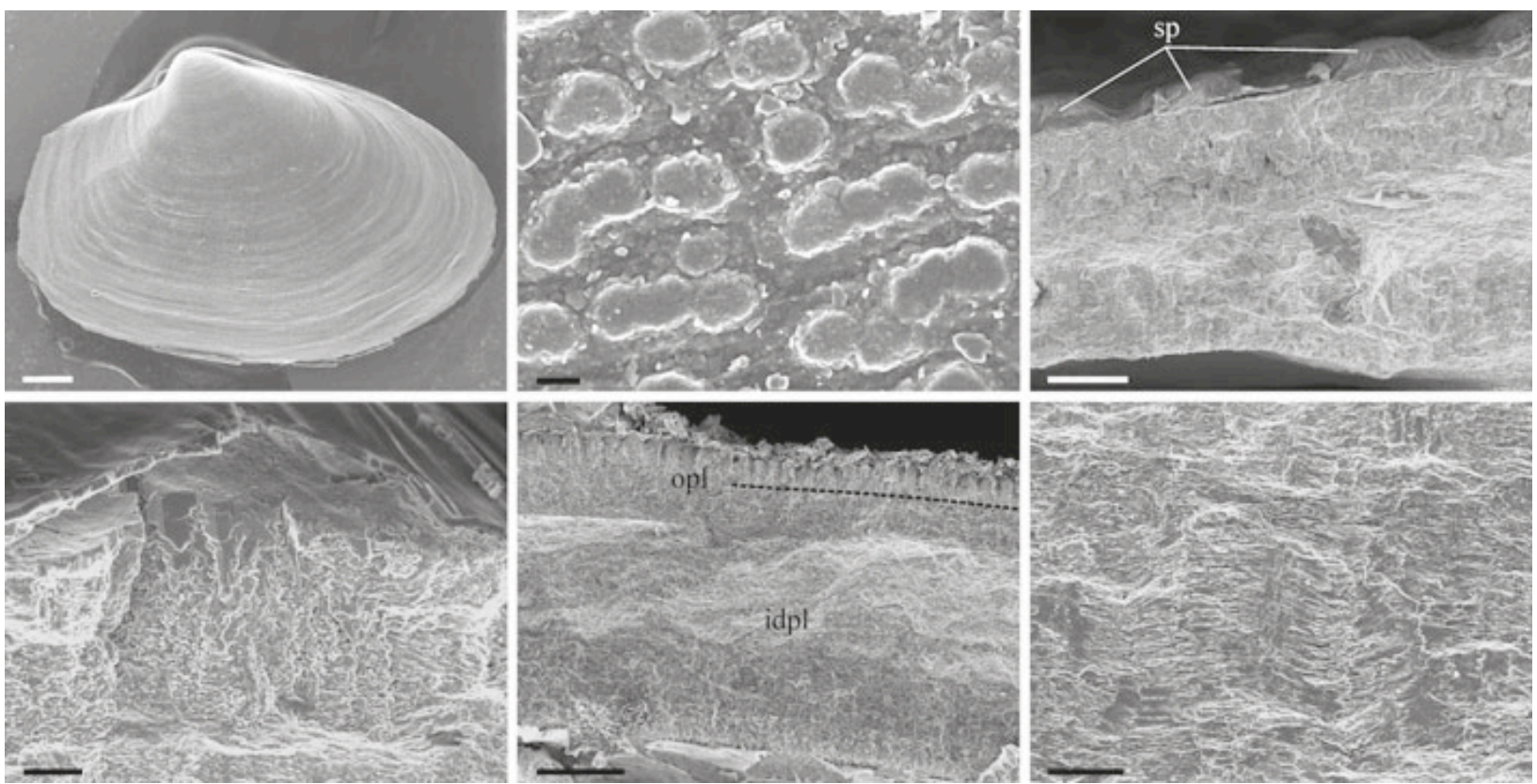

Fig. 1. A. Specimen of Thracia phaseolina (right valve). Scale bar $=0.5 \mathrm{~mm}$. B. Fracture through the shell of $T$. phaseolina showing the outer prismatic layer (opl) derived from spikes and the inner dendritic prismatic layer (ispl). The broken line indicates the approximate boundary between both layers. Scale bar $=20 \mu \mathrm{m}$. C. General view of the shell of $T$. similis, close to the margin. sp, spikes. Scale bar $=50 \mu \mathrm{m}$. D. Detail of the surface of $T$. phaseolina, showing the dense arrangement of spikes. Scale bar $=2 \mu \mathrm{m}$. E. Detail of a spike of $T$. similis and its periostracal cover. The spike is composed of solid prismatic material which changes into fibrous prismatic towards the shell interior. Scale bar $=10 \mu \mathrm{m}$. F. Shell interior of $T$. similis, showing the aspect of the dendritic prismatic layer in fracture. Scale bar $=10 \mu \mathrm{m}$.

\section{Results}

\section{Shell microstructure}

The shells of Thracia spp. are more or less equivalve and inequilateral, with a truncated posterior margin and a rounded anterior margin (Fig. 1A). The shells are thin, ranging from $\sim 180 \mathrm{~lm}$ in thickness in a $5 \mathrm{~mm}$ long specimen of T. phaseolina, to almost $0.5 \mathrm{~mm}$ in the $51 \mathrm{~mm}$ long specimen of $\mathrm{T}$. convexa that was examined. The external surfaces of shells are studded with "periostracal spikes," a term which encompasses a range of morphologies from sharp-tipped to more flattened plaques, but which are formed in the same manner, similar to those displayed by many other anomalodesmatans (Checa \& Harper 2010). The morphology, dimensions, and distribution of these spikes varied among the different species studied. In general, the spikes observed in members of Thraciidae are conical when complete, although once exposed on the surface of the shell they are prone to breakage at the apices.

In $T$. phaseolina, the entire valve surface is densely covered with small spikes ( 4-5 $\mathrm{lm}$ in diameter; Fig. 1B), while in $T$. similis and in the juvenile shell of T. convexa, the spikes are much larger $(80-120 \mathrm{~lm}$ in diameter and $\sim 20$ $1 \mathrm{~m}$ high), though more sparse, with wider inter-spike shell areas (Fig. 1C-E). Such variability of spike morphology and distribution has also been observed in the little known thraciid Thraciopsis angustata (ANGAS 1867) (Checa \& Harper 2010). In Th. angustata, spikes are apparently no longer produced once the shell has attained approximately half its final size. Spikes have a low conical aspect and are encased by periostracal matter, which forms radial wrinkles around the spike flanks (Fig. 1C,E).

In $T$. phaseolina the conical spikes continue into the shell as prisms, which occupy all the available volume and constitute a continuous outer shell layer $\sim 30-40 \mathrm{~lm}$ thick (Fig. 1B) similar to that described in other anomalodesmatans by Taylor et al. (1973) and Checa \& Harper (2010). In T. similis, the spikes are embedded within the outer shell layer (Fig. 1C,D). In both species, the shell between and below the spikes is made of a material which consists of sub-horizontal fibers, which frequently shift their orientation (Fig. 1B,C,E,F), so as to be reminiscent of crossedlamellar microstructure (Fig. 1F).

The existence of natural voids within the shells of $T$. similis and $T$. convexa (particularly within the outer-most half of the shell thickness; Fig. 1C) allowed us to establish the exact nature of the units which constitute the shell. They consist of stacked fibers which radiate perpendicular to a central axis (Fig. 2A-G). Units are predominantly perpendicular to the shell surface, although there is usually some degree of obliquity, with some units being even horizontal. The individual constituent fibers extend between 1-5 lm from the central axis, and become longer toward the central parts of the stacks (Fig. 2D-G). Their transversal dimensions range between $100 \mathrm{~nm}$ to almost $1 \mathrm{~lm}$. Early in their growth these fibers are short and thin, but as they grow they expand laterally to become more lath-like (Fig. 2F-H). Fibers are bounded by crystalline faces (Fig. 2D-H). The transverse outlines range from pseudo-hexagonal equidi 

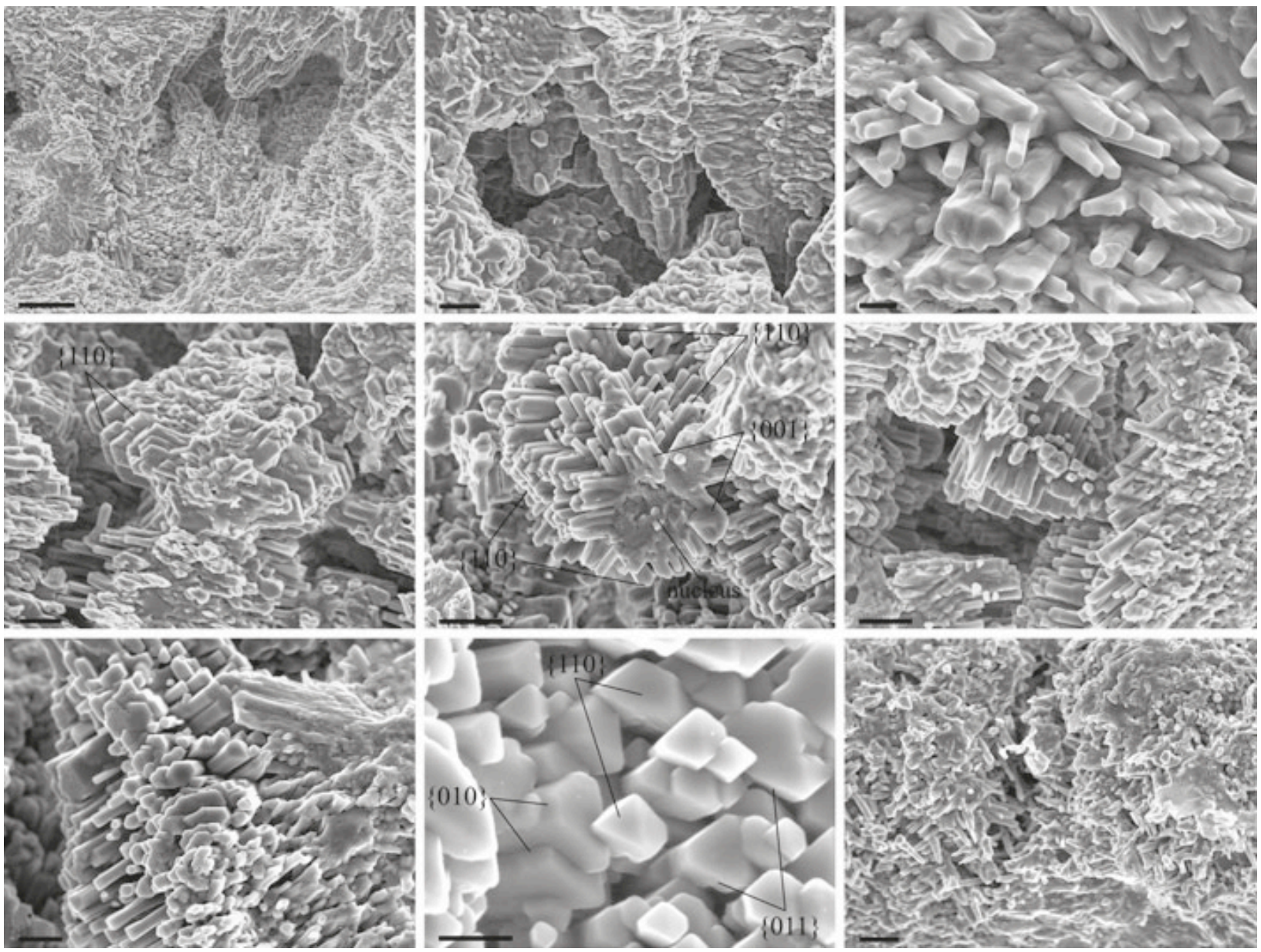

Fig. 2. Scanning electron micrographs of shells of Thracia spp. A, B. Areas of the shells of T. similis (A) and T. convexa (B) with uncalcified voids, making it possible to discern the prismatic units. These tend to be oriented perpendicularly to the valve margin, although the degree of scattering is high, with some units being even horizontal. The fibrous units display prismatic endings. Scalebars $=5 \mu \mathrm{m}$. C-E. Details of some horizontal units in T. similis (C, E) and T. convexa (D) showing the three-rayed arrangement of fibers. Note incipient dendritic growth in C and $\mathrm{E}$, in which lower order fibers grow from bigger fibers, and wide arrow point endings of fibers. The upper flat surfaces are $\{001\}$ aragonite planes (indicated in D and E). The solid core is also evident in the fractured fibrous unit displayed in E. Scalebars $=0.5 \mu \mathrm{m}(\mathrm{C})$ and $2 \mu \mathrm{m}(\mathrm{D}, \mathrm{E})$. F-H. Progressive close-up side views of the fibers composing the units of $T$. similis. The crystalline horizontal, vertical and oblique faces are evident in this view. Some $\{010\},\{011\}$ and $\{110\}$ faces have been labeled in H. Scalebars $=2 \mu \mathrm{m}(\mathrm{F}), 1 \mu \mathrm{m}(\mathrm{G})$ and $0.5 \mu \mathrm{m}(\mathrm{H})$. I. Aspect of the fibrous shell interior of $T$. phaseolina. Some groups of fibers diverge at $60^{\circ}$ angles. Scalebar $=2 \mu \mathrm{m}$.

mensional to almost rhombic due to reduction of the lateral faces (Fig. 2H). Some of the wider fibers appear to consist of other smaller fused fibers (Fig. 2G). The units formed by the stacks of fibers are terminated by prismatic ends consisting of fused vertically arranged fibers (Fig. 2A,B). In section, the stacked units show a central massive core that is more or less continuous into the prismatic endings (Fig. $2 \mathrm{E})$. In the free units examined, the horizontal fibers intersect at some $60^{\circ}$, thus forming a six-rayed pattern, which is particularly evident when the main units are sectioned perpendicular to the longitudinal axis (Fig. 2D-E). In some instances, fibers may emit other minor fibers at $60^{\circ}$, thus forming incipient dendritic crystals (Fig. 2C,E).

Unfortunately, the absence of similar voids in $T$. phaseolina prevented us from determining if the constituent units are of the same nature as those described above, although the existence of associated thin needles into groups radiating at $60^{\circ}$ is evident (Fig. 2I).

\section{Mantle and periostracum}

Examination of the ventral mantle margins of members of the three species revealed that the middle and inner mantle folds are fused, i.e., fusion type B of Yonge (1957, p. 182), as had been reported in Trigonothracia jinxingae XU 1980 by Morton (1995) and T. meridonalis SMITH 1885 by Sartori \& Domaneschi (2005). The outer mantle fold (OMF) is conspicuously bilobate as also reported in $T r$. jinxingae by Morton (1995). The periostracum emerges from a periostracal groove at the base of the OMF (Fig. $3 \mathrm{~A}$ ), although the position of the groove is particularly difficult to locate due to its minute size. Unfortunately, the fixation of our material was not adequate to permit us to observe the initiation of the periostracum at the basal cell or equivalent structure. However, once apparent within the periostracal groove, the periostracum consists of a thin (30$50 \mathrm{~nm}$ thick) outer dark homogeneous layer, and a thicker 

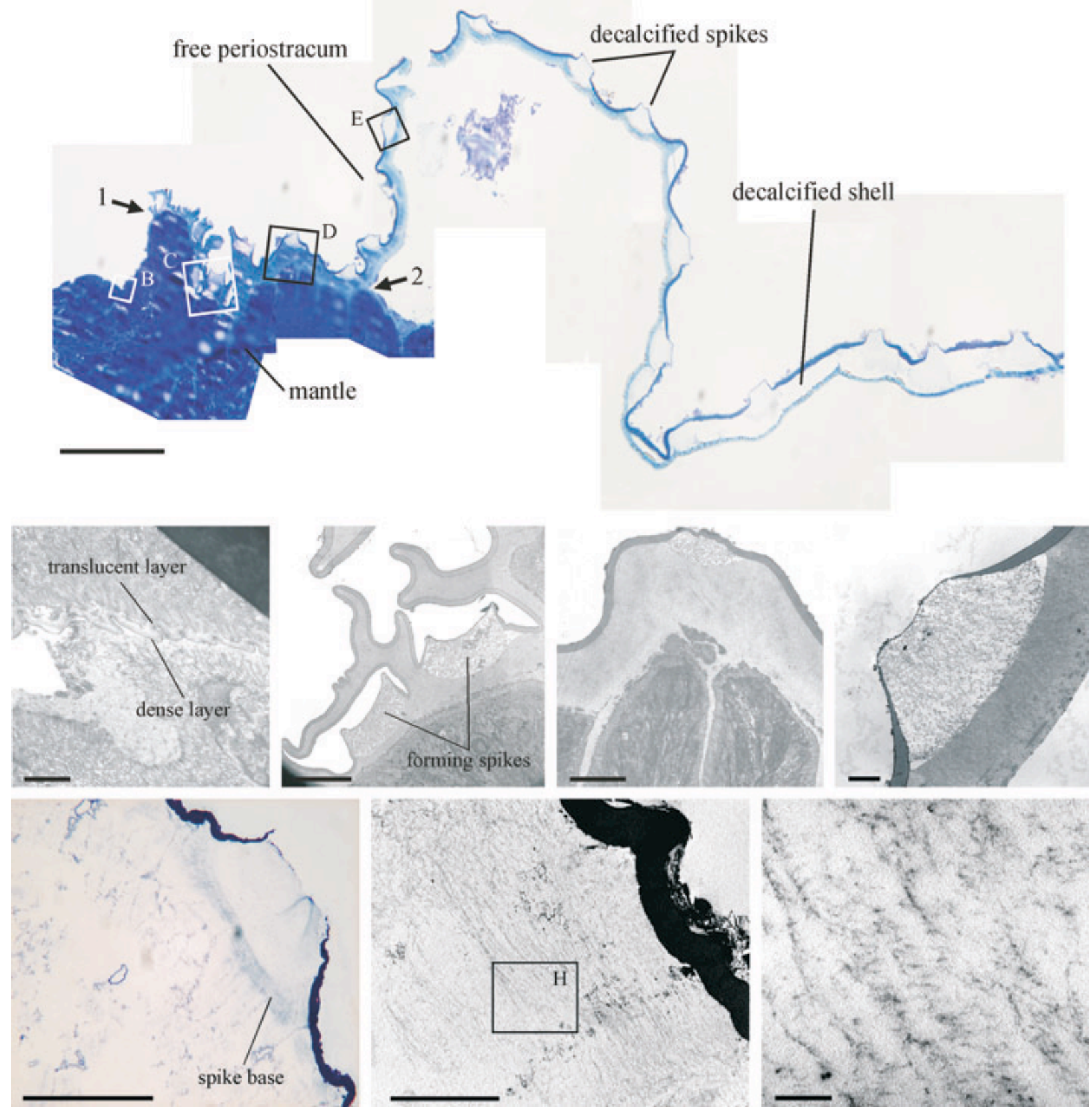

Fig. 3. Sections through the shells of Thracia spp. A. Thin section through the mantle and decalcified shell of T. phaseolina. The arrows indicate the positions at which the periostracum either suddenly increases in thickness (1) or detaches from the mantle (2). Scalebar=50 $\mu \mathrm{m}$. B-E. Transmission electron micrographs showing details of the specimen shown in A. Their positions in A are indicated with the labeled squares. B. Detail of the periostracum within the periostracal groove. Scalebar $=1 \mu \mathrm{m}$. C. Forming periostracum with spikes adhered to the outer mantle fold (OMF) epithelium. Scalebar $=5 \mu \mathrm{m}$. D. Forming periostracum at the external lobe of the OMF. Note thickening of both periostracal layers compared to C. Scale bar $=5 \mu \mathrm{m}$. E. Decalcified spike and corresponding free periostracum. Scalebar $=2 \mu \mathrm{m}$. F. Thin section through a spike in a decalcified shell of T. similis. The boundary between the spike and the outer shell layer is marked by a different distribution of the organic membranes. Scalebar $=50 \mu \mathrm{m}$. G. Transmission electron micrograph of the decalcified shell of $T$. similis, with horizontal membranes as well as spaced jagged vertical membranes. Square labeled H is shown in H. Scalebar $=5 \mu \mathrm{m}$. H. Detail of G showing the aspect of horizontal membranes. Scalebar $=200 \mathrm{~nm}$.

$(150-300 \mathrm{~nm})$, more translucent inner layer (Fig. 3B), which itself has a layered aspect. The inner layer is clearly secreted by the microvillate cells lining the periostracal groove of the OMF (Fig. 3B,C). The thickness of the periostracum increases as it slides over the surface of the OMF, with a particularly dramatic increase in thickness from the edge of the more internal lobe of the OMF (Fig. 3A, arrow
1). Sections made at this position show that the periostracum may become heavily wrinkled locally (Fig. 3C), and that both the outer dark and inner translucent layers increase in thickness toward the shell edge (compare Fig. 3C to $3 \mathrm{D}$ ). Detachment of the periostracum at the tip of the external lobe of the OMF marks the onset of the "free" periostracum stage (Fig. 3A, arrow 2). 
In the studied sections, the first periostracal spikes appear at the tip of the internal lobe of the OMF, coincident with the observed sudden periostracal thickening (Fig. 3A, arrow 1). Spikes invariably nucleate at the boundary between the dark and the translucent layers (Fig. 3A,C-E). The dark layer which covers the spikes typically thins toward the tips of the spikes (Fig. 3C, E). In decalcified sections, at a distance of some 200-250 $1 \mathrm{~m}$ after detachment of the periostracum from the OMF, spikes expand laterally until they coalesce. Further in the distal direction, the two periostracal layers begin to separate progressively, with the intervening space being filled by a loose membranous material, at the same time that the translucent layer becomes thinner (Fig. 3A). This indicates that shell calcification initiates within the periostracum, and proceeds from the boundary between the two periostracal layers toward the shell interior. Thinning of the translucent layer also implies that the growing aragonitic material gradually incorporates the translucent material.

Decalcified shell sections reveal the existence of organic membranes within the shell itself (Fig. 3F, G). These may be divided into two types. Most are flat, aligned parallel to the periostracum surface (Fig. 3G, H), and extremely thin (Fig. $3 \mathrm{H}$ ). Other organic material appears as jagged lines which run more or less perpendicular to that surface, thus clearly depicting the outlines of the prismatic units forming the shell, described below (Fig. 3F,G).

Decalcified spikes show a diffuse distribution of organic matter, which is not organized into membranes except for some radially aligned remains (Fig. 3F). These differences in distribution of the organic matter, which are easily discerned in decalcified samples, form the basis for identifying the approximate boundary between the spikes and the rest of the shell.

\section{Transmission electron microscopy}

It was difficult to discern the boundaries between the prismatic units in ultrathin sections, except when diffraction contrast imaging allowed us to partially trace their outlines (Fig. 4A). Additional evidence was provided by the shapes of sectioned individual fibers. According to whether the sections appear elongate or as equidimensional polygons, we were able to establish whether fibers had been sectioned more or less perpendicular or transverse to their main axis, respectively. In those areas in which fibers are loosely packed, STEM imaging allowed us to observe their third dimension (Fig. 4B).

The lattice spacings obtained by FFT were in all cases consistent with those of aragonite. Examination and indexing of fibers which appeared elongated in section implied that the [001] direction is perpendicular to the main axis of the fiber section, while the fiber section itself coincides in several cases with [110] (Fig. 4A-C). In perpendicular sections the two in plane directions are [001] and [010], which indicates that we were looking at the fiber from the [100] direction (Fig. 4D-I). In general, TEM data indicate that fibers grow along the aragonite [100] direction (a-axis), and that they stack up along [001] (c-axis).

\section{Discussion}

\section{Periostracum formation and shell calcification}

We were not able to observe the initiation of the periostracum, and so our observations begin from the distal part of the periostracal groove, where the periostracum is already a thin membrane $(200 \mathrm{~nm})$ composed of an outer dark and an inner translucent layer (Fig. 3B). Although both layers increase their thickness as the periostracum slides along the inner surface of the OMF, thickening is particularly marked for the translucent layer. The type, number, and mode of thickening of periostracal layers is similar to that reported in other bivalves in general (Bevelander \& Nakahara 1967; Neff 1972; Bubel 1973; Saleuddin 1974; Salas et al. 2011), and in anomalodesmatans in particular (Checa \& Harper 2010). The latter authors also explained that, as in Thracia spp., thickening of the dense layer can only be produced by tanning of the translucent layer, since at the free periostracum stage (Fig. 3A) there is no epithelium bounding the external surface of the periostracum.

The spikes observed in Thracia spp. grow in a similar way to those reported in other anomalodesmatan bivalves (Checa \& Harper 2010). Spikes grow intraperiostracally and initiate at the boundary between the dark and translucent layers. The first spikes are observed at the tip of the inner lobe of the OMF (Fig. 3A), but given their relatively advanced growth, spikes may well initiate earlier and thus closer to the periostracal groove. The dense layer typically thins toward the spike tips. This is because toward the center of the spike the portions of dark layer were in progressively more incipient growth stages when they were underlain by the mineralizing spike, thereby preventing further thickening (Checa \& Harper 2010, fig. 12B). During their passage along the free periostracum, spikes continue to grow by absorbing the material forming the translucent layer.

Judging from what we know from other anomalodesmatans (Harper et al. 2009; Checa \& Harper 2010) and from our observations on the decalcified sections of $T$. phaseolina (Fig. 3A), calcification in members of the genus Thracia clearly progresses from the base of the dark periostracal layer, or from the base of the spikes (when present), toward the shell interior. Thinning of the translucent layer implies that its organic material is progressively incorporated by the forming crystals, as evidenced by the presence of horizontal nanometer-sized membranes found within the decalcified shell crystals (Fig. 3F-H). The same process was reported in the spikes and shell interior of Laternula rostrata SOWERBY 1842 (Checa \& Harper 2010). In members of $T$. phaseolina, shell thickening seems 

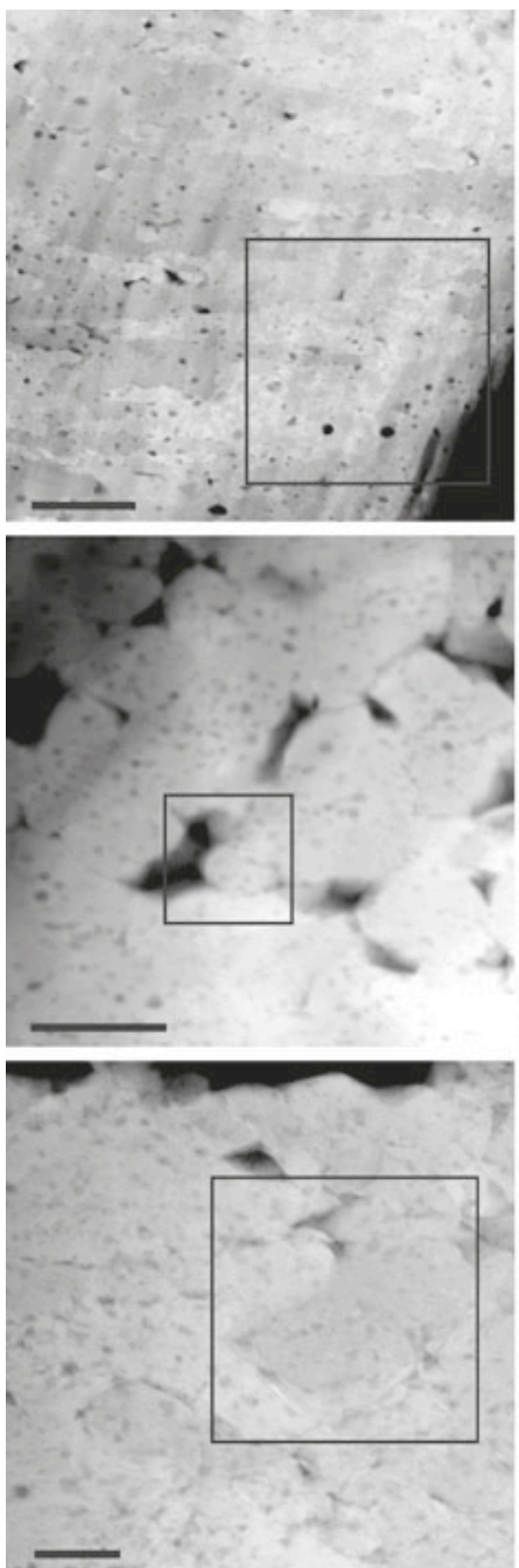
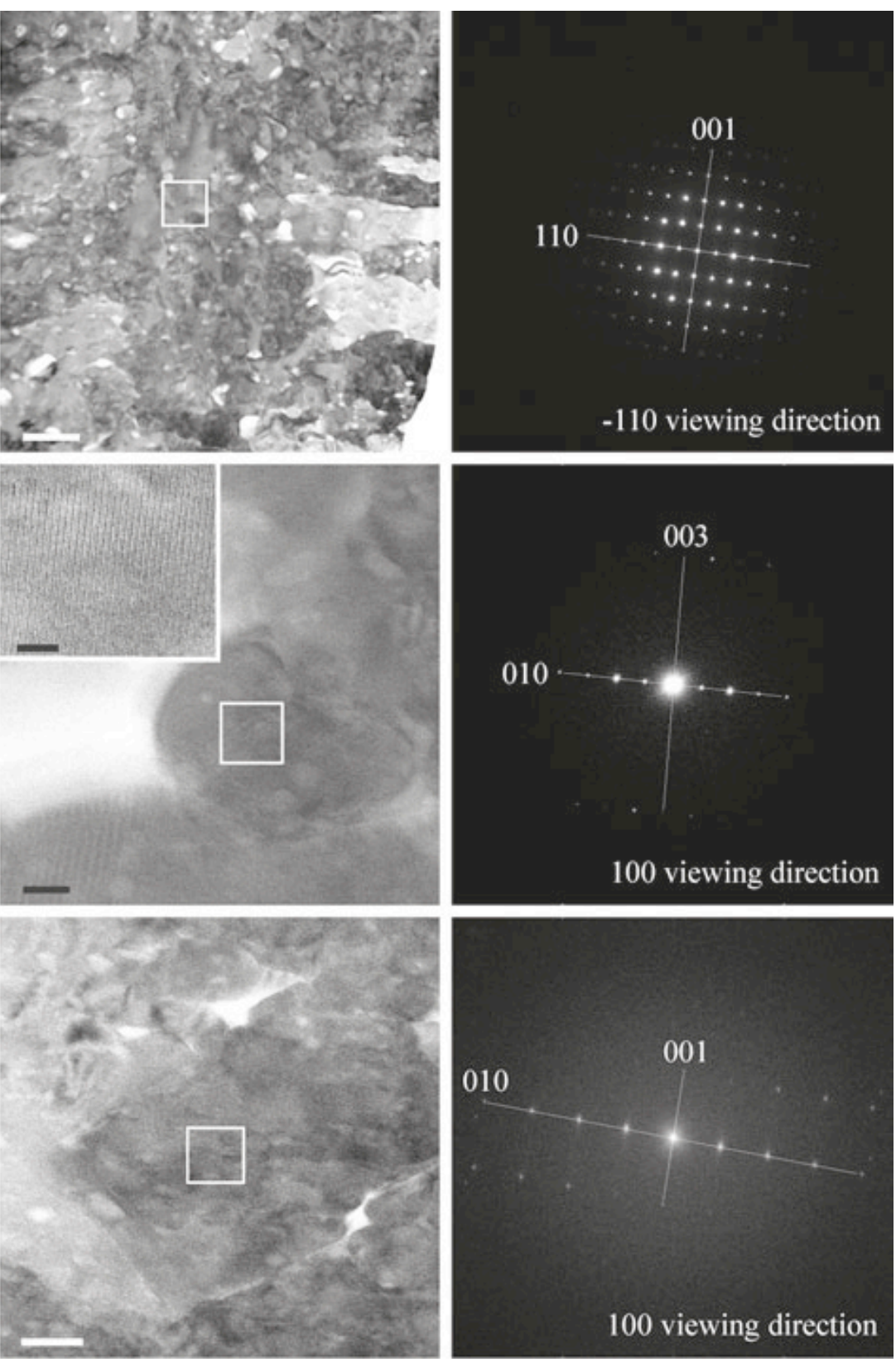

Fig. 4. Transmission electron micrographs of the dendritic prismatic units of Thracia similis. A-C. Area in which the fibers have been cut transversely at a small angle. A. Scanning transmission electron microscope (STEM) view of the area shown in B (framed in A). Scalebar=1 $\mu$ m. B. Phase contrast transmission electron micrograph. Scalebar $=0.0055 \mu \mathrm{m}$. C. Indexed Fast Fourier Transform (FFT) of the small area framed in B, showing that the c-axis is perpendicular to the long axis of the fibers and that these have been sectioned along an intermediate direction between the a- and b-axes. D-I. Two cases in which the fibers have been sectioned perpendicular to their main axes. D. STEM far views of the areas analyzed in E. Scale bar=200 nm. E. Closer views of the area indicated in D. The inset in E is a close up view of the small square, and clearly shows the crystal lattice. Scale bars=20 nm (E), $5 \mathrm{~nm}$ (inset in E). F. Indexed FFTs of the area framed in E. showing that the a-axis is along the fiber axis. G. STEM far views of the areas analyzed in H. Scale bar=100 nm. H. Closer view of the area indicated in G. Scale bar=50 nm. I. Indexed FFTs of the areas framed in $\mathrm{H}$, indicating that the a-axis is along the fiber axis.

to progress slowly and the cross section of the ventral valve edge is very thin, whereas in $T$. similis calcification is faster and the valve thickens more rapidly away from the very edge.

We cannot determine precisely how much of the shell layer thickness of members of Thracia is strictly intraperiostracal. In T. phaseolina, at least the outer prismatic layer is formed within the translucent periostracum (Fig.
3A), but we have no data on the underlying layer thickness. No data are available on other species of the genus. The voids observed within the shell interior in $T$. similis and $T$. convexa (Figs. 1C, 2A-G) most probably correspond to incomplete calcification of the translucent layer.

Judging from what we know from other anomalodesmatans (Harper et al. 2009; Checa \& Harper 2010) and from our observations on the decalcified sections of 

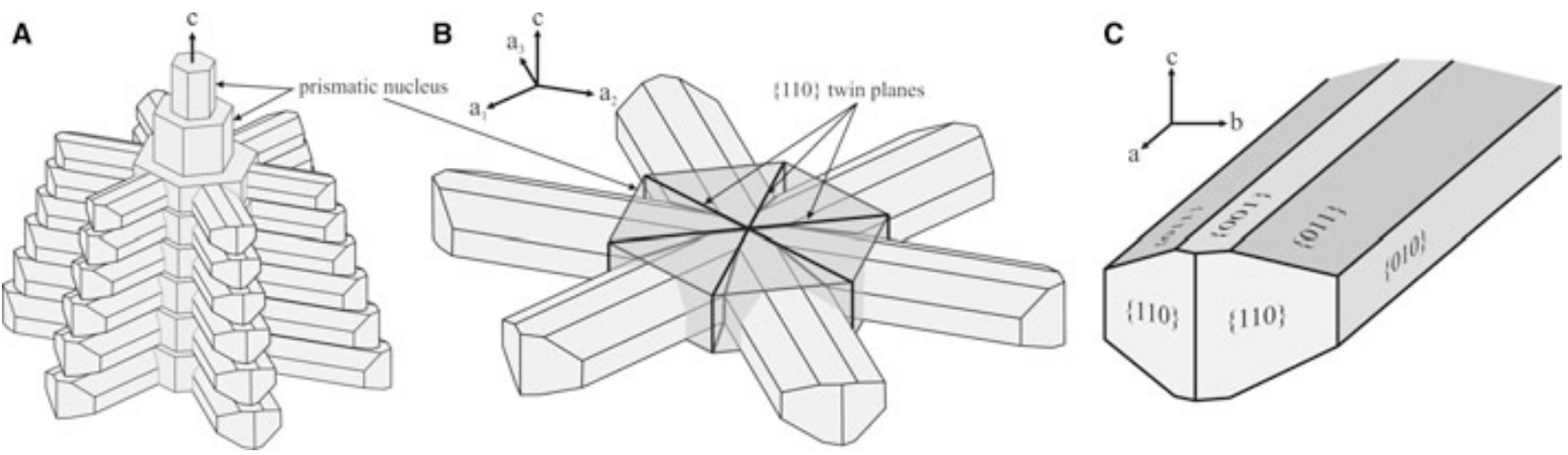

Fig. 5. Models of shell microstructures of Thracia spp. A. Diagram of the structure of a dendritic prism. It is composed of a prismatic core from which fibers radiate with a six-rayed arrangement. Fibers increase in length toward the center of the prismatic unit. The endings are purely prismatic. The c-axis is along the prism axis. B. Basic structure of a horizontal unit. It is composed of six fibers with their a-axes parallel to the long axis of the fibers and twinned on $\{110\}$. C. Theoretical fiber showing all the crystal faces (indexed) recognized in actual fibers.

Thracia phaseolina (Fig. 3A), calcification in the genus Thracia clearly progresses from the base of the dark periostracal layer, or from the base of the spikes (when present), towards the shell interior. Thinning of the translucent layer implies that its organic material is progressively incorporated by the forming crystals as evidenced by the presence of horizontal nanometer-sized membranes found within the decalcified shell crystals (Fig. 3F-H). The same process was reported in the spikes and shell interior of Laternula (Checa \& Harper 2010). In Thracia phaseolina, shell thickening seems to progress slowly and the cross section of the ventral valve edge is very thin, whereas in $T$. similis calcification is faster and the valve thickens more rapidly away from the very edge.

We cannot determine precisely how much of the shell layer thickness of Thracia is strictly intraperiostracal. In T. phaseolina, at least the outer prismatic layer is formed within the translucent periostracum (Fig. 3A), but we have no data on the underlying layer thickness. No data are available on other species of the genus. The voids observed within the shell interior in $T$. similis and $T$. convexa (Fig. 1C, 2A-G) most probably correspond to incomplete calcification of the translucent layer.

\section{Crystallography of microstructural units}

As described above, the microstructural units consist of stacked up horizontal fibres which diverge at $90^{\circ}$ from a central vertical axis (Fig. 2A, F, G). The two ends of the units are typical prismatic (Fig. 2A, B). The fibres typically meet at angles of $60^{\circ}$ (Fig. 2C-E, I). The TEM data imply that the main axis is the $c$-axis (Fig. 4) and that the horizontal fibres grow along the $a$-axis (Fig. 5A). This is consistent both with the $c$-axis being the longitudinal one in aragonite prisms and with the angle of $116.21^{\circ}$ between either $a$ - or $b$-axes of aragonite crystals which are associated by the typical $\{110\}$ polycyclic twin (Fig. 5B). These basic references allow us to index the main faces developed by fibres.
All crystal faces found in $T$. similis are indexed in the ideal fibre depicted in Fig. 5C; some actual faces have also been indexed in Fig. 2D, E, H. The outlines of the faces indexed as $\{110\}$ when seen in frontal (e.g., Fig. 2G-H) and top views (e.g., Fig. 2D, E) accord to the typical relationships of the aragonite unit cell dimensions (a:b:c $=0.62: 1: 0.72$ ).

These stacked units may be defined as prismatic because they are elongated along the c-axis. However, they differ from more typical prismatic structures seen elsewhere in the molluscs because of they are composed of second order units which radiate from the central core, at times branching, and we propose the term 'dendritic prisms' to differentiate them from other prism-types, for example those in unionoids which are more solid (Checa 2000). These dendritic prisms terminate with typical prismatic endings (Fig. 5A, B). The central core possibly represents the early stages of growth of the initial solid prism as it grows along the $c$-axis which, after a certain width has been attained, 2-3 $\mu \mathrm{m}$ wide (judging by the extent of the solid core; Fig. 2E), the growth of which then converts in to a dendritic prism.

Besides prismatic microstructures (e.g., the granular prismatic microstructure myostracal prisms), the only other microstructure which shares similarities with the dendritic prismatic microstructure of members of Thracia is the foliated aragonite of monoplacophorans. It consists of laths that are flat along the $c$-axis and, as the fibres of $T$. spp., elongate along the $a$-axis (Checa et al. 2009a). To explain this peculiar morphology, Checa et al. (2009b) hypothesized that growth along the $c$ - and $b$-axes is inhibited due to absorption of organic molecules onto the aragonite $\{001\}$ and $\{010\}$ surfaces respectively. In contrast, growth along the $a$-axis is not inhibited because the distance between the calcium atoms and the $\mathrm{CO}_{3}$ groups is the shortest along this axis, which results in the existence of chains of strong bonds and therefore, in a reduced probability of absorption of organic molecules. A similar process could perhaps be invoked for the fibres found in Thracia, although it must 
somehow be size dependent in order to explain the transition from prism growth to fibre growth at a given size.

\section{Relationship to other anomalodesmatan microstructures}

Shell microstructural types are frequently employed as characters in polygenetic analyses of the bivalves (e.g., Tëmkin 2006; Waller 2006). Recent work has highlighted the problems of interfering microstructure from examination of larger-scale structures, such as the columnar calcite prisms which are common to many pteriomorph taxa (e.g., Carter 1980) but which, with more detaled crystallographic investigatin, were realized to be constructed in different ways (Esteban-Delgado 2008). It is therefore important to establish whether or not similar appearing microstructure are truly homologous, or even whether those of rather different appearance distinct.

\section{References}

Bevelander G \& Nakahara H 1967. An electron microscope study of the formation of the periostracum of Macrocallista maculata. Calcif. Tissue Res. 1: 55-67.

Bøggild OB 1930. The shell structure of molluscs. K. Dansk. Vid. Selsk. Sk. Naturv. Math. Afd. 9: 233-326.

Bubel A 1973. An electron-microscope study of periostracum formation in some marine bivalves. I. The origin of the periostracum. Mar. Biol. 20: 213-221.

Carter J G 1980. Environmental and biological controls of bivalve shell mineralogy and microstructure. In: Skeletal Growth of

Aquatic Organisms. Rhoads DC \& Lutz RA eds., pp 69-113. Plenum, New

York.

Carter JG 1990. Chapter 10. Evolutionary significance of shell microstructure in the Palaeotaxodonta, Pteriomorphia and Isofilibranchia (Bivalvia: Mollusca). In: Skeletal Biomineralization: Patterns, Processes and Evolutionary Trends. Volume I. Carter JG ed., pp. 135-296. Van Nostrand Reinhold, New York.

Carter JG, Campbell DC \& Campbell MR 2000. Cladistic perspectives on early bivalve evolution. Geological Society of London, Special Publication 177: 47-79.

Checa A 2000. A new model for periostracum and shell formation in Unionidae (Bivalvia, Mollusca). Tissue \& Cell 32, 405-416.

Checa A \& Harper EM 2010. Spikey bivalves: intra-periostracal crystal growth in anomalodesmatans. Biol. Bull. (Woods Hole) 219: $231-248$

Checa AG, Ramírez-Rico J, González-Segura A \& Sánchez-Navas A 2009a. Nacre and false nacre (foliated aragonite) in extant monoplacophorans (=Tryblidiida: Mollusca). Naturwissenschaften 96: 111-122.

Checa AG, Sánchez-Navas A \& Rodríguez-Navarro A 2009b. Crystal growth in the foliated aragonite of monoplacophorans (Mollusca). Cryst. Gr. Des. 9: 4574-4580.

Geiger, DL, Nützel A \& Sasaki, T 2008. Vetigastropoda. In: Phylogeny and Evolution of the Mollusca. Ponder, WF \& Lindberg DR, eds., pp. 297-330. University of California Press, Berkeley.
As explained above, the dendritic prismatic layer is produced by calcification of the internal translucent periostracum. In this sense, therefore, despite their apparent distinctiveness, dendritic prisms are homologous with the outer granular prismatic or prismatic layer of other anomalodesmatans. Rather, they constitute a variant produced by the association of aragonite prisms with particular organic molecules.

\section{Acknowledgments.}

Serge Gofas and Carmen Salas are thanked for providing specimens of Thracia phaseolina. Funding was provided by Projects CGL2007-60549, CGL2010-20748C02-01 (DGI, MICINN) and Research Group RNM190 (PAI, JA) as well as the projects REDE/1509/RME/2005 and PTDC/CTM/100468/2008 of the Portuguese Foundation for Science and Technology (FCT).

Harper EM, Dreyer H \& Steiner G 2006. Reconstructing the Anomalodesmata (Mollusca: Bivalvia): morphology and molecules. Zool. J. Linn. Soc. 148: 395-420.

Harper EM, Checa AG \& Rodríguez-Navarro AB 2009 Organization and mode of secretion of the granular prismatic microstructure of Entodesma navicula (Bivalvia: Mollusca). Acta Zool. 90: $132-141$.

Jackson DJ, McDougall C, Woodcroft B, Moase P, Rose RA, Kube M, Reinhardt R, Rokhsar DS, Montagnani C, Joubert C, Piquemal D \& Degnan BM 2010. Parallel evolution of nacre building gene sets in molluscs. Mol. Biol. Evol. 27: 591-608.

Marie B, Marin F, Marie A, Bédouet L, Dubost L, Alcaraz G, Milet C \& Luquet G 2009. Evolution of nacre: biochemistry and proteomics of the shell organic matrix of the cephalopod Nautilus macromphalus. Eur. J. Chem. Biol. 10: 1495-1506.

Morris NJ, Dickins JM, Astafieva-Urbaitis K 1991. Upper Palaeozoic anomalodesmatan bivalves. Bull. Br. Mus. Nat. Hist. (Geol.) 47: 51-100.

Morton B 1995. The ecology and functional morphology of Trigonothracia jinxingae (Bivalvia: Anomalodesmata: Thracioidea) from Xiamen, China. J. Zool. 237: 445-468.

Neff JM 1972. Ultrastructural studies of periostracum formation in the hard shelled clam Mercenaria mercenaria (L). Tissue Cell 4: 311-326.

Prezant RS 1981. Comparative shell ultrastructure of lyonsiid bivalves. The Veliger 23: 289-299.

Runnegar B 1974. Evolutionary history of the bivalve subclass Anomalodesmata. J. Paleontol. 48: 904-939.

Salas CP, Marina AG, Checa A \& Rueda JL in press. The periostracum of Digitaria digitaria (Bivalvia: Astartidae): formation and structure. J. Molluscan Stud.

Saleuddin ASM 1974. An electron microscopic study of the formation and structure of the periostracum in Astarte (Bivalvia). Can. J. Zool. 52: 1463-1471.

Salvini-Plawen Lv \& Steiner G 1996. Synapomorphies and plesiomorphies in higher classification of Mollusca. In: Origin and evolutionary radiation of the Mollusca. Taylor, ed., pp 29-51. Oxford University Press, Oxford. 
Sartori AF \& Domaneschi O 2005. The functional morphology of the Antarctic bivalve Thracia meridonalis Smith, 1885 (Anomalodesmata: Thraciidae). J. Molluscan Stud. 71: 199-210.

Schneider JA \& Carter JG. 2001. Evolution and phylogenetic significance of cardioidean shell microstructure (Mollusca, Bivalvia). J.

Paleontol. 75: 607-643.

Taylor JD 1973. The structural evolution of the bivalve shell. Palaeontology 16: 519-534.

Taylor JD, Kennedy WJ \& Hall AD 1969. The shell structure and mineralogy of the Bivalvia. Introduction, NuculaceaTrigonacea. Bull. Br. Mus. Nat. Hist. (Zool.) Suppl. 3: 1-125.

Taylor JD, Kennedy WJ \& Hall AD 1973. The shell structure and mineralogy of the Bivalvia. II. Lucinacea-Clavagellacea, Conclusions. Bull. Br. Mus. Nat. Hist. (Zool.) 22: 225-294.
Taylor JD \& Layman M 1972. The mechanical properties of bivalve (Mollusca) shell structures. Palaeontology 15: 73-87.

Vendrasco M, Checa A \& Kouchinsky A 2011. Shell microstructure of the early bivalve Pojetaia and the independent origin of nacre within the Mollusca. Palaeontology 54: 825-850.

Waller, T R 2006. Phylogeny of families in the Pectinoidea (Mollusca: Bivalvia): importance of the fossil record. Zool. J. Linn. Soc. 148: 313-342.

Wingstrand KG 1985. On the anatomy and relationships of Recent Monoplacophora. Galathea Rep. 16: 7-94.

Yonge CM 1957. Mantle fusion in the Lamellibranchia. Pubbl. Stn. Zool. Napoli 29: 151-171. 